\title{
It's time we paved a healthier path of least resistance
}

897 words, 14 references

Jessica A Renzella ${ }^{1}$, Dr Alessandro R Demaio*2

1. Centre on Population Approaches for Non-Communicable Disease Prevention, Nuffield Department of Population Health, University of Oxford

2. World Health Organization, Geneva, Switzerland

*corresponding author: demaioa@who.int

Inspiring and retaining interest, investment, and action to prevent tomorrow's health threats today is notoriously difficult. This is particularly true when the resulting future wellbeing may not be realised for years, or even decades. The outcome is a lack of political and societal prioritisation for disease prevention, accompanied by a pernicious rise in avoidable health burden.

Obesity is now the biological, environmental and social path of least resistance in most societies. Despite being entirely avoidable, an estimated 1.9 billion adults and 41 million children under five years are overweight, worldwide ${ }^{1,2}$. Addressing the drivers of obesity through evidence-based structural and political responses is key, yet such action largely continues to evade us.

But what if we could shape obesity solutions as rapidly as we build our cities? What if our cities could make achieving and maintaining healthy weight easier?

\section{Our cities are not designed for health}

For the first time in history, more than half of the global population lives in cities, and almost four in every ten adults are overweight or obese ${ }^{1,3}$. With obesity and urbanisation on the rise, the built environments in which people work, live, eat, and move are increasingly recognised to have a profound influence on the health, wellbeing, and waistlines of populations $s^{4,5}$.

City living is associated with a multitude of health opportunities and challenges. Better access to more advanced healthcare, education, employment, and other services are juxtaposed with increasingly obesogenic, sprawling, and polluted urban environments ${ }^{6,7}$.

In less than half-a-century, many urban food systems worldwide have shifted from a base of minimally processed and seasonal food staples to one of highly processed, energy dense, ubiquitous, and aggressively marketed junk foods ${ }^{5}$. Dietary risks are now a leading cause of global morbidity and mortality, with overweight, obesity, and undernutrition often coexisting in the same individual, household, community, and country ${ }^{8}$. In low- and middleincome countries (LMICS) - while still burdened by undernutrition - overweight and obesity are on the rise. In Sri Lanka, a country experiencing rapid urbanisation, adult obesity prevalence is already almost three-fold higher in urban versus rural populations ${ }^{9}$. 
These altered food as well as activity environments have established an imbalance between energy consumed and expended, rendering urban living an established risk factor for obesity and other noncommunicable diseases (NCDs) ${ }^{4,5}$. A health threat that is most pronounced among poorer communities in wealthier countries, and in $\mathrm{LMICs}^{10}$.

\section{Co-designing a healthier path of least resistance}

The answer is not to force health on populations or unreasonably limit individual choice. Rather, it is to use health-promoting urban design to ensure the easiest and preferred options for transport, housing and diet are also the healthiest. For example, by considering the six accepted characteristics of urban planning that support active transport ${ }^{11}$, we gain a more granular understanding of how healthy urban planning can address physical inactivity:

1. Urban design that incorporates active transport infrastructure;

2. Density of design with multiunit, medium-density housing that provides sufficient demand for public services and transport investments;

3. Distance to transit that prioritises public transport accessibility;

4. Diversity of housing, providing different housing options with services to support liveability;

5. Destination accessibility with public facilities less than 30-minutes travel from home; and

6. Desirability, including increasing green space quality and availability.

Education, awareness campaigns, and pharmacological interventions are essential, but they are insufficient to solve our global obesity epidemic ${ }^{6}$. To achieve sustained health improvements in an increasingly urbanised world, city planners and health professionals must work together and be supported by context-specific urban policy frameworks. For example, the Amsterdam Healthy Weight Programme is based upon a framework that supports shared responsibility for overweight and obesity across all policy areas at the city level leading to productive collaborations between the Public Health Service and the Department of Physical Planning.

\section{Overcoming complexities with co-benefits}

Cities are complex and dynamic ecosystems and the relationship between urban planning and health outcomes can appear overwhelming and uncontrollable. Obesity, therefore, provides a powerful narrative for healthier urban approaches. Tackling obesogenic environments through clever policy provides an opportunity to simultaneously improve food systems and activity environments with co-benefits for climate change and other dimensions of human health (cardiovascular disease, type 2 diabetes, stroke, cancer, mental health).

Participatory urban agriculture, including community gardens, is one example of an intervention that could improve general health ${ }^{12}$, reduce food waste and insecurity ${ }^{13}$, promote physical fitness ${ }^{14}$, positively impact social cohesion and mental health ${ }^{14}$, create urban green spaces, and provide employment opportunities ${ }^{13}$. Presently though, much of what we know about solutions with co-benefits is based on small-scale projects, necessitating greater research. 
The foundations for healthy urban policy already exist. From cycle-friendly streets in Chennai and investments in public transport infrastructure in Singapore, to Amsterdam's whole city government approach to healthy weight, and park revitalisation projects in Mexico City - the future is here, and it's healthy. We must continue to monitor, evaluate, implement, and scale existing urban-health initiatives, and share success stories of multisectoral collaboration.

We can no longer ignore the global obesity epidemic nor our growing urban challenges. The message is simple: city planning must prioritise people over profits, and health above all. The following principles may enable the achievement of this bold call to action:

1. Prioritise health at every stage of planning

2. Build cities for and with community

3. Integrate monitoring, evaluation and reporting activities

4. Champion design with co-benefits (for people and planet)

5. Invest in evidence-informed solutions alongside innovation

Dr Alessandro Demaio is a staff member of the World Health Organization in Geneva. He alone is responsible for any views expressed in this publication and they do not necessarily represent the decisions or policies of any third party.

\section{References}

1. NCD Risk Factor Collaboration. Trends in adult body-mass index in 200 countries from 1975 to 2014: a pooled analysis of 1698 population-based measurement studies with 19.2 million participants. The Lancet 2016;387(10026):1377- 1396.

2. UNICEF, WHO, World Bank Group. Levels and trends in child malnutrition. Key findings of the 2017 edition. New York/Geneva/Washington DC: The United Nations Children's Fund, the World Health Organization and the World Bank Group, 2017 [cited 29 August 2017]. Available from: https://data.unicef.org/wpcontent/uploads/2017/05/JME-2017-brochure-1.pdf

3. UN. World Urbanization Prospects: The 2014 Revision, Highlights. United Nations Department of Economic and Social Affairs, Population Division, 2014.

4. Allender S, Wickramasinghe K, Goldacre M, Matthews D, Katulanda P. Quantifying Urbanization as a Risk Factor for Noncommunicable Disease. Journal of Urban Health : Bulletin of the New York Academy of Medicine 2011;88(5):906-918.

5. Popkin BM. Urbanization, lifestyle changes and the nutrition transition. World Dev 1999;27:1905-16.

6. Swinburn B, Egger G, Raza F. Dissecting obesogenic environments: the development and application of a framework for identifying and prioritizing environmental interventions for obesity. Preventive Medicine 1999;29:563-70.

7. WHO. WHO Global Urban Ambient Air Pollution Database (update 2016). Geneva: World Health Organization, 2017 [cited 29 August 2017]. Available from: http://www.who.int/phe/health topics/outdoorair/databases/cities/en/

8. WHO. The double burden of malnutrition: Policy brief. Geneva: World Health Organization. 2017. 
9. Katulanda P, Jayawardena MA, Sheriff MH, Constantine GR, Matthews DR. Prevalence of overweight and obesity in Sri Lankan adults. Obes Rev 2010;11(11):751-6.

10. WHO. Global report on urban health: equitable, healthier cities for sustainable development. Geneva: World Health Organization, 2016.

11. Giles-Corti, B et al. City planning and population health: a global challenge. The Lancet 2016;388(10062):2912 - 2924

12. Maas J, Verheij A, Groenewegen PP, de Vries S, Spreeuwenberg P. Green space, urbanity, and health: how strong is the relation? J Epidemiol Community Health 2006;60:587-592.

13. Forster T, Egal F, Getz Escuerdo A, Dubbeling M, Renting H. Milan Urban Food Policy Pact. Selected Good Practices from Cities. Milan: Fondazione Giangiacomo Feltrinelli. 2015.

14. Soga M, Cox DTC, Yamaura Y, Gaston KJ, Kurisu K, Hanaki K. Health Benefits of Urban Allotment Gardening: Improved Physical and Psychological Well-Being and Social Integration. Int. J. Environ. Res. Public Health 2017;14(1):71. 